تأثير رش بعض العناصر الصغرى وإضافة حامض الهيومك في صفات الجذور ومحتوى الاورلق من العناصر الغذائية لتبات الفاصوليا الخضراء.

\author{
ماجد علي حنشل \\ استاذ مساعد
}

باحث علمي حامد الاليمي*

قسم البستنة وهندسة الحدائق -كلية الزراعة

njahhamd@gmail.com

المستخلص

نفذت التجرية في المحطة البحثية التابعة لكلية الزراعة- جامعة بغداد للموسمين الربيعي والخريفي لعام 2015 ،استخدم في الزراعة

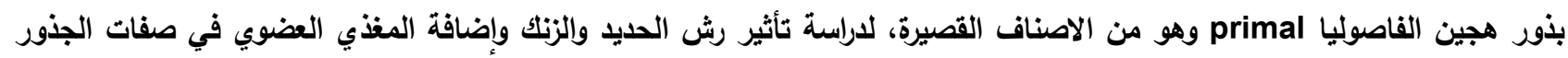

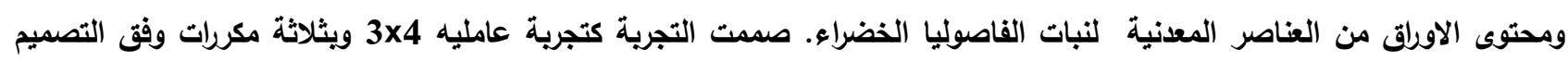

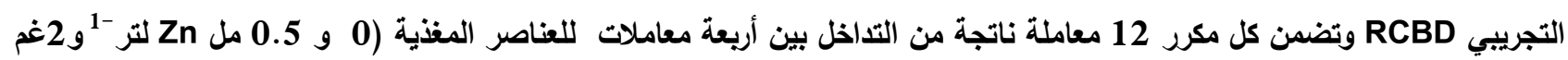

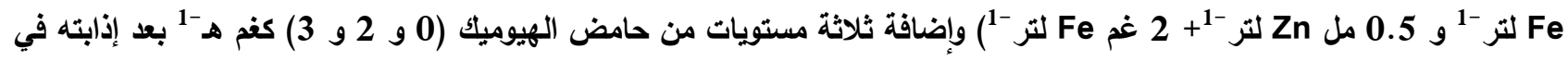

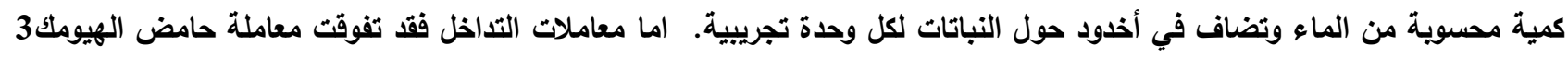

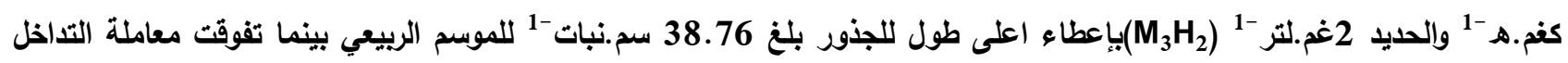

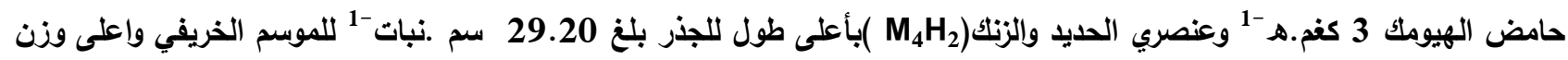

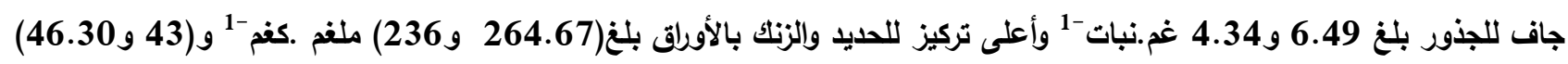

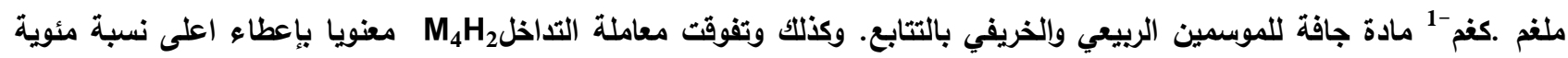

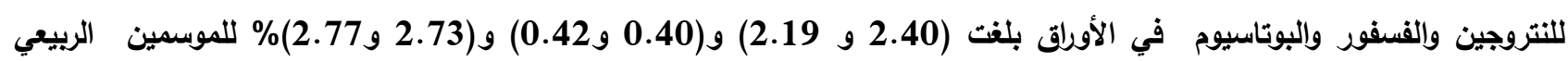
والخريفي بالتتابع الكلمات المفتاحية : حامض الهيوميك ، الحديد ، الزتك ، الفاصوليا. "البحث مستل من رسالة ماجستير الباحث الاول.

The Iraqi Journal of Agricultural Sciences -660-670: (3) 48/ 2017 Al-DULAIMI \& Al-JUMAILI

\title{
EFFECT SPRAYING SOME MICRONUTRIENTS AND ADD HUMIC ACID IN TRAITS OF ROOTS AND LEAVES CONTENT OF NUTRIENTS IN GREEN BEANS
}

\section{N. H. Al-DULAIMI*}

Research.

\section{M.A. Al-JUMAILI}

Assist. Prof.

Dept. of Horticulture and Landscape Gardening - College of Agriculture-University of Baghdad njahhamd@gmail.com

\section{ABSTRACT}

An experiment was carried out at the research station of the Agriculture College - of Baghdad University for two seasons, spring and autumn 2015, Using hybrid seeds, primal, one of the early Cultivars. To study the effect of iron, zinc spray and add organic nutrient for the vegetative growth and plant yield of green beans. The experiment was conducted using factorial experiment $(4 \times 3)$ with in randomized complete block designe with three replicates and12 treatments resulting from

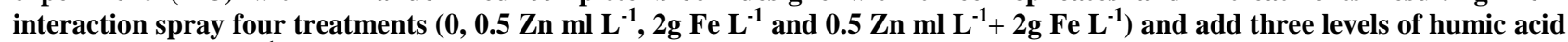
$(0,2$ and 3$) \mathrm{kg} \mathrm{ha}^{-1}$, after melted in a calculated amount of water and insert into the groove around the plants per experimental unit. The results showed the superiority of the treatment $\left(\mathrm{M}_{3} \mathrm{H}_{2}\right)$ humic acid $3 \mathrm{~g} . \mathrm{ha}^{-1}$ and iron $2 \mathrm{~g} . \mathrm{L}^{-1}$ it the highest length of the roots $\left(38.76 \mathrm{~cm}\right.$. Plant $\left.{ }^{-1}\right)$ for spring season, while superiority treatment $\left(\mathrm{M}_{4} \mathrm{H}_{2}\right) \mathrm{Humic}$ acid $3 \mathrm{~g}$.ha' ${ }^{-1}$ elemental iron, zinc length of the root amounted $29.20 \mathrm{~cm}$.Plant ${ }^{-1}$ for autumn season, highest weight of dry roots $(6.49$ and 4.34 q. plant $^{-1)}$, superiority treatment $\mathrm{M}_{4} \mathrm{H}_{2}$ in highest concentration of iron and zinc in leaves amounted $(264.67,236) \mathrm{mg}^{-\mathrm{kg}^{-}}$ 1 and $(43.00,46.30) \mathrm{mg} \mathrm{kg}^{-1}$ dry mater seasons of spring and autumn on respectively. Superiority the treatment of $\mathrm{M}_{4} \mathrm{H}_{2}$ significantly by giving highest percentage of nitrogen, phosphorus and potassium in leaves $(2.40,2.19),(0.40,0.42)$ and $(2.73$, 2.77)\% for two seasons, spring and autumn respectively.

Keyword :Humic acid ,Iron ,Zinc, Green bean.

*Part of M.Sc. Thesis of first author . 
حديد) وAmino-green (2.9 ( حديد) على نباتات الفاصوليا أدت إلى زيادة في محتوى الأوراق من عناصر

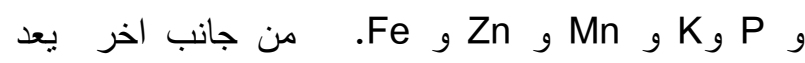
عنصر الزنكك من العناصر الصغرى الضرورية لنمو وإكمال

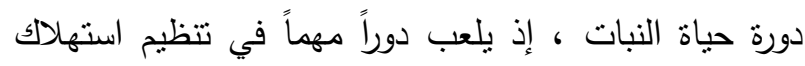

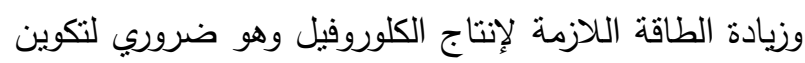
الحامض الأميني التربتوفان الذي له دور في تكوين النشا (11). اذ أجرى Nejad وآخرون (28) دراسة على نبات الفاصوليا حيث رش النباتات بتسعة مسنويات من كبريتات

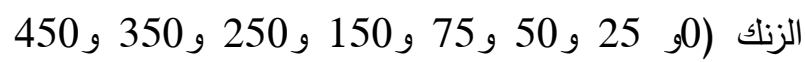

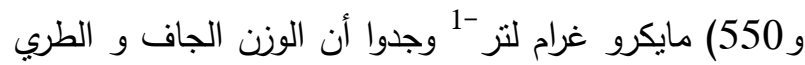

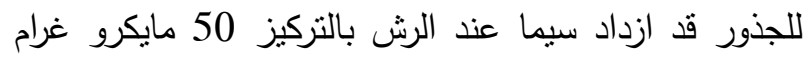

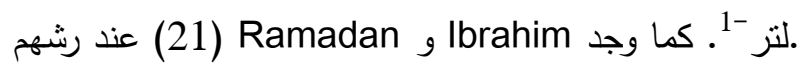
نبات الفاصوليا صنف Nebraska بتركيز 100 ملغم لتر -1

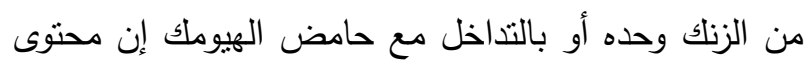

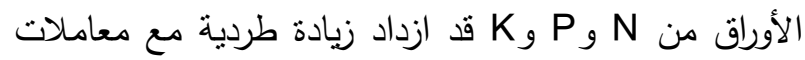
الرش. اما المادة العضوية فهي احد المصادر المهمة لكثير

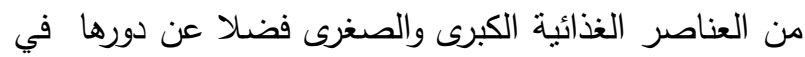
زيادة جاهزية العناصر الغذائية في التربة من خلال محتواها

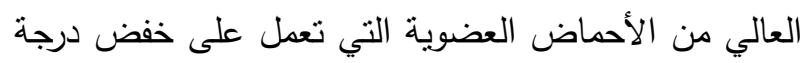
تفاعل التربة وذوبان بعض المركبات غير الذائبة (29)(31)

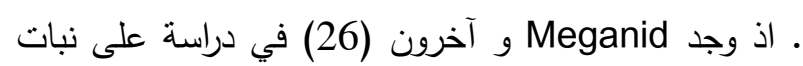
الفاصوليا اذ اضيف لكل نبات 3 غم لتر -1 من حبييات Pوجدوا أن الوزن الطري و الجاف وعدد الجذور قد ازداد مع اضافة حامض الهيوميك ـ. إذ بين El-khatib

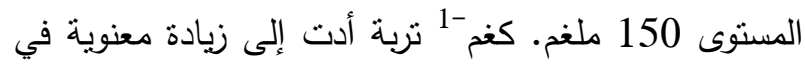
محتوى النتروجين والفسفور والبوتاسيوم في أوراق نباتات

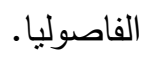

\section{المواد وطرائق العمل}

نفذت التجربة في محطة البحوث الزراعية في كلية الزراعة -جامعة بغداد للموسمين الربيعي والخريفي 2015 لدراسة

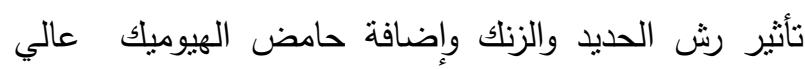
البوتاسيوم في صنات الجذور ومحتوى الاوراق من العناصر

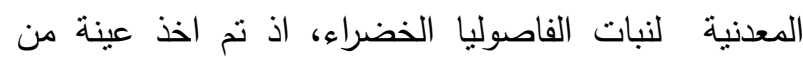
التربة قبل الزراعة ومن( 9) مواقع مختلفة من الحقل بمستوى لتبه
المقدمة

Phaseolus ) Green bean تتنمي الفاصوليا الخضراء (vulgaris L. تعد من اكبر العائلات النباتية ويضم الجنس Phaseolus

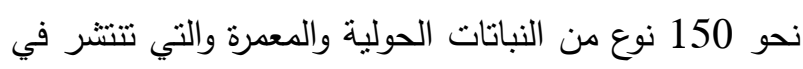

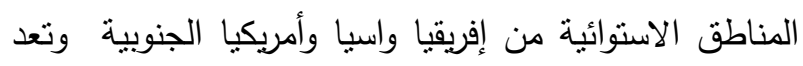

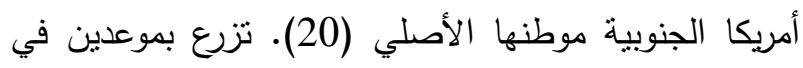
العراق أحدهما ربيعي ابتداءً من آذار وتعطي حاصلها في الاصني بداية أيار والآخر خريفي تزرع في أواخر آب وبداية أيلول وتعطي حاصلها في تشرين الثاني (8)، كما أنها غنية بالفيتامينات والألياف وتحتوي على بعض المعادي فئل مثل الحديد بضعف الكمبة مقارنة بالسبانغ فضلا عن المغنيسيوم والكالسيوم والفسفور والبوتاسيوم والنحاس والزنكك والفيتامينات والفلافونيدات والكاروتينات، كذللك لها دور مهم في تجهيز

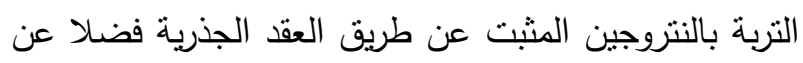
مردودها الاقتصادي العالي (22) و (23). وتتصف كثير من ترب المناطق الجافة وشبه الجافة ومنها ترب العراق باحتوائها على نسبة عالية من كاربونات الكالسيوم والتي تصل إلى 500ملغم كغم -1 مما تسبب في رفع درجة تفاعل هذه الترب وجعلها تميل للقاعدية مما يؤدي إلى قلة جاهزية العناصر المعدنية الصغرى كالحديد والزنك والمنغنيز ، والتي لها دور

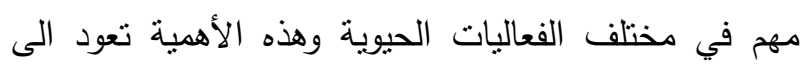
دخولها في تركيب ونشاط كثير من الانزيمات المختلفة

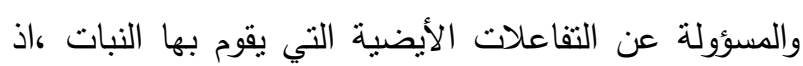
أنشار Abu Dahi و و Al-Younis (2) بأن للحديد دوراً في مساعدة تكوين الكلوروفيل بالرغم من انه لا يدخل في تكوينه، وكذلك يدخل في تكوين السايتوكرومات ذات الأهمية الكبيرة

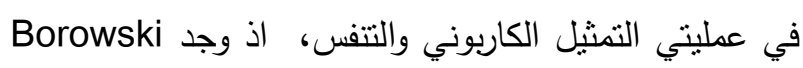
و Michaáek (13) أن رش أملاح الحديد على نباتات

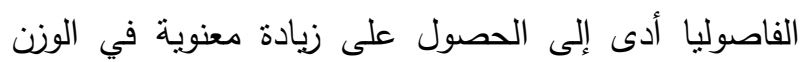

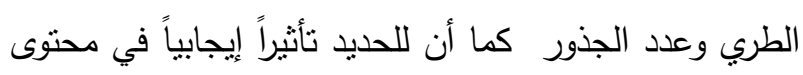

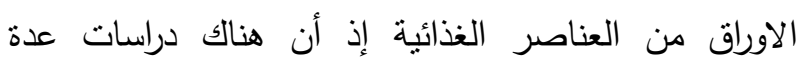

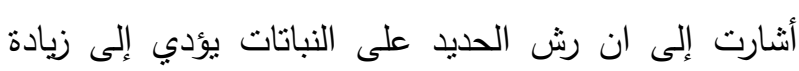
أمنصاص النباتات للعناصر الغذائية ومن ثم زيادة محتواها من ثلك العناصر اذلاحظ Abdel-Mawgoud و آخرون \% Manni-Plex أن رش المحاليل المغذية 
جدW HUMUS Pنول 2. محتويات السماد العضوي

\begin{tabular}{|c|c|}
\hline القيمة (\%) & التركيب \\
\hline 12 & الرطوبة \\
\hline 99.8 & الاتحلال (الذوبان في الماء) \\
\hline 85 & هيومات البوتاسيوم \\
\hline 11 & البوتاسيوم \\
\hline 86 & المادة الجافة \\
\hline 0.8 & النتروجين \\
\hline 1.0 & الحديد \\
\hline 15 & مواد أخرى \\
\hline
\end{tabular}

نفذت تجربة عرمان عاملية (3x4) بحسب تصميم القطاعات الكاملة المعشاة RCBD وبثلات قطاعات ويتضمن كل قطاع (12) وحدة تجربيية مساحة الوحدة التجريبية 3م2 وتحوي

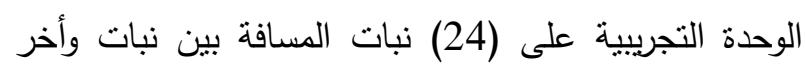
25 سم وزرعت على جانبي المرز بالتبادل وباستخدام نظام

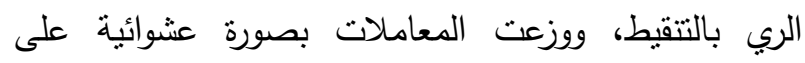
المكررات وحللت البيانات وقورنت المتوسطات باستخدام اقل

فرق معنوي (LSD) على مستوى احتمال 5\% (19). الصفات المدروسة معنية

1. طول الجذر (سم): قيست أطوال جذور النباتات لخمسة نباتات أخذت من كل وحدة تجريبية في نهاية كل موسم بعد الند رفع الكيس الحاوي على النبات والمدفون في تربه الحقل للحصول على جذور سليمة.

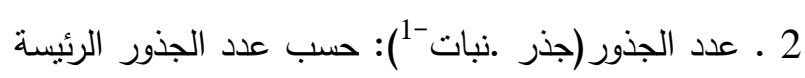
لخمسة نباتات أخذت من كل وحدة تجريبية في نهاية كل موسم واخذ المتوسط . 3 ـ الوزن الجاف للجذور (غم. نبات -1): نم حساب الوزن . الجاف لجذور لخمسة نباتات من كل وحدة تجريبية وغسلت بالماء جيداً ثم جفقت جيداً بقطعة قماش وأخذ الوزن الرطب كن وحة لها ووضعت في أكياس ورقية وجفقت العينات في فرن

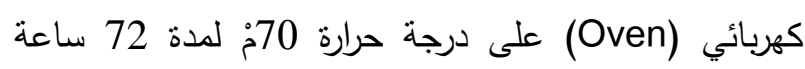
لحين ثثوت الوزن ثم أخرجت ووزنت بميزان حساس وراخذ المتوسط (9). 4 ـ تقدير نركيز العناصر في الأوراق. أخذت الورقة الرابعة من الاعلى لخمس نباتات من كل وحدة تجريبية بصورة عشوائية في مرحلة الإزهار (9). قدر النتروجين الكلي

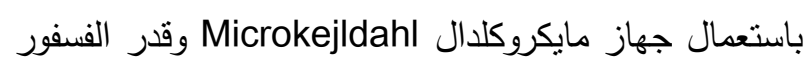
بطريقة مولبيدات الامونيوم وعند تطور اللون الأزرق قرئ

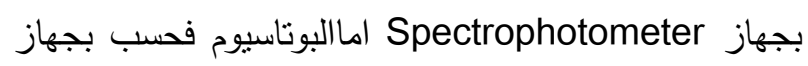
Flame photometer
عمق (0-30) سم وخلطت العينات مع بعضها ثم غربلت بغربيل قطر 2 ملم واخذ منها نموذج واحد لغرض تحليل الصفات الكيميائية والفيزيائية لتربة الحقل والنتائج مبينة في نياتي الجدول(1)، وأجريت عملية حراثة الأرض المخصصة للزراعة بوساطة المحراث القلاب وبصورة متعامدة وبعد الجداث التسوية والتتعيم تم تقسيم الحقل إلى ثلاثة قطاعات ويتضمن

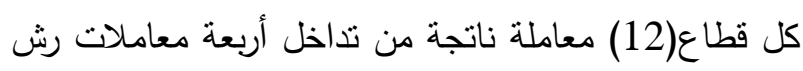

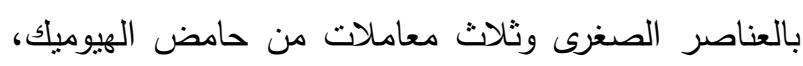
زرعت بذور هجين الفاصوليا Primel (من الاصناف

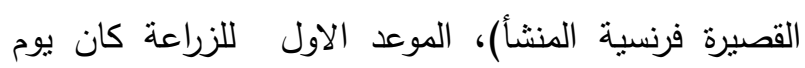

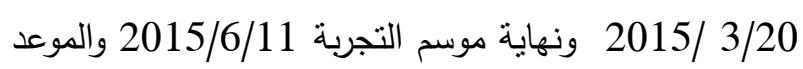
الثاني يوم 2015/9/10 ونهاية موسم التجربة 9 2015/12، وكانت المعاملات كالاتي: العامل الاول أربعة

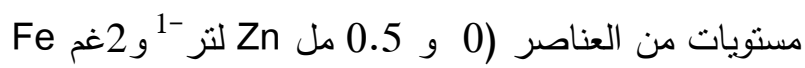

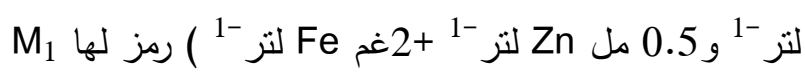

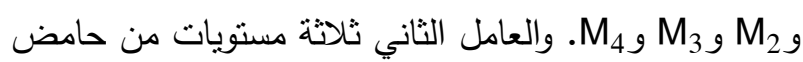

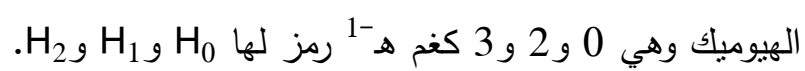
رشت عناصر الحديد والزنك المخلبي على المجموع الخضري وبثلاثة رشات، الرشة الأولى بعد مرور شهر من الزراعة

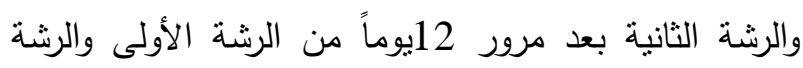

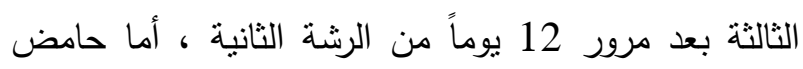

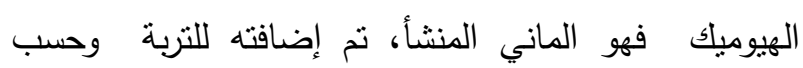

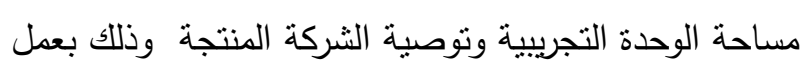

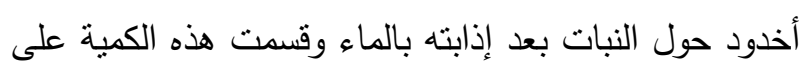

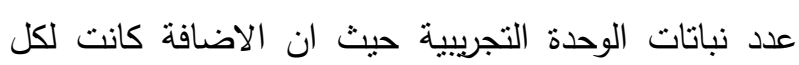
نبات نصف لنز ، وكانت الإضافة الأولى بعد 33 يوم من

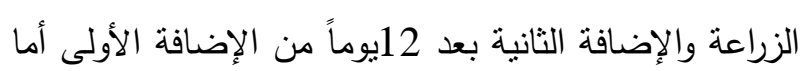
الإضافة الثالثة بعد 12 يوم من الإضافة الثانية (7). جدول1. تحليل خصائص التربة الفيزيائية والكيميائية

\begin{tabular}{|c|c|c|}
\hline الخريفي & الربيعي & الصفة \\
\hline 7.04 & 7.15 & pH \\
\hline 2.21 & 2.33 & $\mathbf{E C}_{1: 1}$ \\
\hline 68.89 & 65.45 & النتروجين الجاهز ملغم. كفم -1 \\
\hline 19.67 & 36.44 & الفسفور الجاهز ملغم. كفم-1 \\
\hline 36.45 & 77.66 & البوتاسيوم الجاهز ملغم .كغم-1 \\
\hline 1.89 & 2.77 & الحديل ملغم. كغم-1 \\
\hline 1.95 & 2.33 & الزتلك ملغم .كغر-1 \\
\hline 27.6 & 28.7 & الطين غم .كغم-1 \\
\hline 48.4 & 49.6 & الغرين غم .كغم-1 \\
\hline 21.9 & 17.8 & الرمل غم. كغم- \\
\hline \multicolumn{2}{|c|}{ طينية غرينية } & نسجة التربة \\
\hline
\end{tabular}


أعطت أعلى طول للجذور بلغ 34.46 و 26.90 سم .نبات Atomic Absorption Spectrophotometer بهاز

1 للموسمين الربيعي والخريفي بالتتابع والتي لم تختلف معنويا

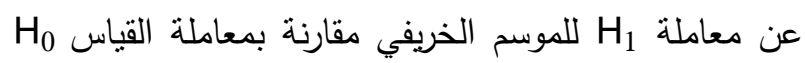
النتائج والمناقشة التي أعطت اقل طول للجذور بلغ 30.08 و 24.08 سم. طول الجذور (سم. نبات -1)

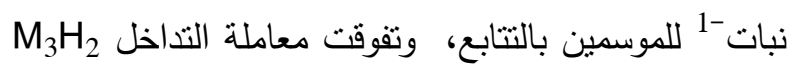
بإعطاء أعلى طول للجذور بلغ 38.76 سم.نبات-1 للموسم

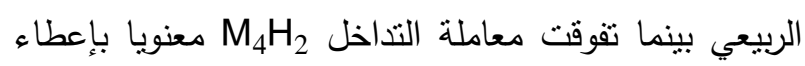

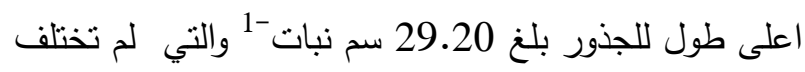
معنويا عن معاملة M M ${ }^{2} \mathrm{H}_{4} \mathrm{H}_{1}$ للموسم الخريفي مقارنة بمعاملة القياس M 28.50و 21.10 سم نبات -1 للموسمين بالتتابع.

يتضح من نتائج جدول3 وجود اختلافات معنوية لمعاملات لونات

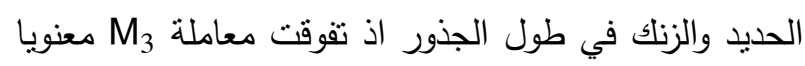
بإعطاء أعلى طول للجذور بلغ 34.63 سم. نبات -1 والتي لم لم

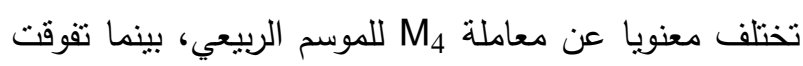
معاملة M معنويا بإعطاء اعلى طول للجذور بلغ 28.06

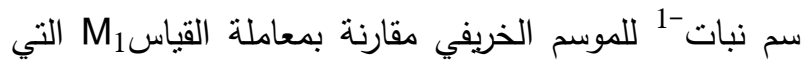

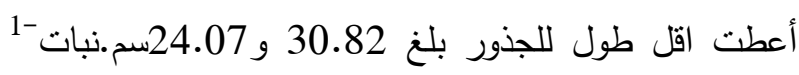

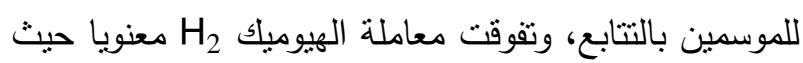
جدول 3 ـ تأثير الرش بالحديد والزتك وإضافة حامض الهيومك وتداخلهما في طول الجذور(سم .نبات-1) لنبات الفاصوليا الخضراء للموسمين الربيعي والخريفي 2015

\begin{tabular}{|c|c|c|c|c|c|c|c|c|c|c|}
\hline \multicolumn{5}{|c|}{ الموسم الخريفي } & \multicolumn{6}{|c|}{ الموسم الربيعي } \\
\hline المتوسط & $\mathbf{M}_{4}$ & $\mathbf{M}_{3}$ & $\mathbf{M}_{2}$ & $\mathbf{M}_{1}$ & المتوسط & $\mathbf{M}_{4}$ & $\mathbf{M}_{3}$ & $\mathbf{M}_{2}$ & $M_{1}$ & المعاملات \\
\hline 24.08 & 26.70 & 25.60 & 22.93 & 21.10 & 30.08 & 31.33 & 29.33 & 30.57 & 28.50 & $\mathbf{H}_{0}$ \\
\hline 26.63 & 28.27 & 28.83 & 25.30 & 24.13 & 34.29 & 35.53 & 35.80 & 32.83 & 33.03 & $\mathbf{H}_{1}$ \\
\hline 26.90 & 29.20 & 26.50 & 24.93 & 26.97 & 34.46 & 35.13 & 38.76 & 33.00 & 30.93 & $\mathbf{H}_{2}$ \\
\hline \multirow[t]{2}{*}{0.824} & \multicolumn{4}{|c|}{1.647} & 0.115 & \multicolumn{4}{|c|}{0.230} & $\begin{array}{c}\text { L.S.D } \\
\mathbf{5 \%}\end{array}$ \\
\hline & 28.06 & $\begin{array}{l}26.98 \\
0.951 \\
\end{array}$ & 24.39 & 24.07 & & 33.99 & $\begin{array}{l}34.63 \\
0.642 \\
\end{array}$ & 32.13 & 30.82 & $\begin{array}{l}\text { المتوسط } \\
\text { L.S.D }\end{array}$ \\
\hline
\end{tabular}

في صفة عدد الجذور للموسم الربيعي ، بينما تفوقت عدد الجذور الثانوية(جذر .نبات -1

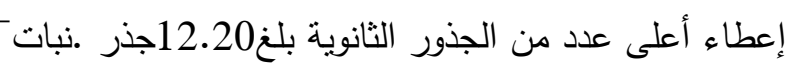

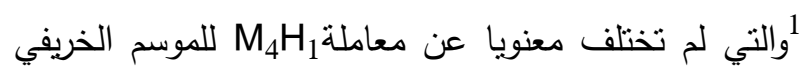
مقارنة بمعاملة القياس M الجذور الثانوية بلغ97.97جذر .نبات -1"للموسم الخريفي. الوزن الجاف للجذور (غم .نبات -1) تشير نتائج جدول 4 إلى وجود فروق معنوية لمعاملات الحديد والزنكك في عدد الجذور الثانوية لنبات الفاصوليا الخضراء اذ تفوقت معاملة M4 بإعطاء أعلى عدد من الجذور الثانوية بلغ 15.25 و 11.06 جذر ننبات -1للموسمين بالتتابع

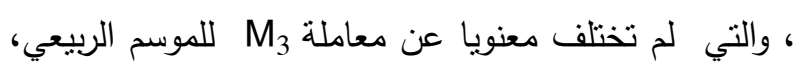
مقارنة بمعاملة القياسM التي أعطت اقل عدد من الجذور تنشير نتائج جدول 5 إلى وجود تأثثر معنوي لمعاملات الحديد والزنك في الوزن الجاف للمجموع الجذري لنباتات الفاصوليا الخضراء إذ تفوقت معاملة M4 معنويا بإعطاء

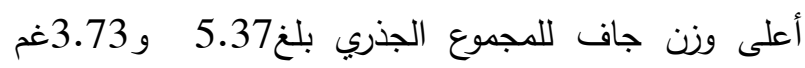

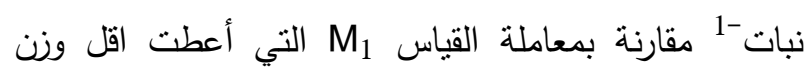
جاف للجذور بلغ 4.08 و 2.58 غم نبات -للموسمين الربيعي

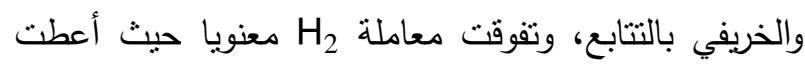

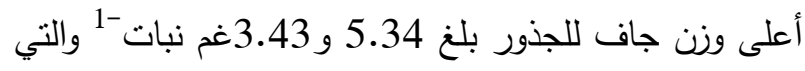
لم تختلف معنويا عن معاملة H مقارنة بمعاملة القياس

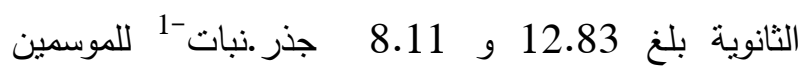
بالتتابع ، بينما لم تظهر معاملة الهيوميك

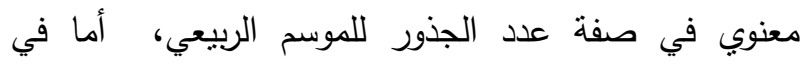

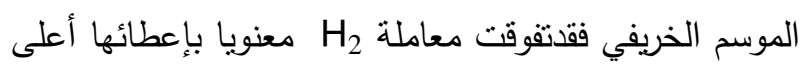
عدد جذور بلغ 10.01 جذر .نبات -1 والتي لم تختلف معنويا

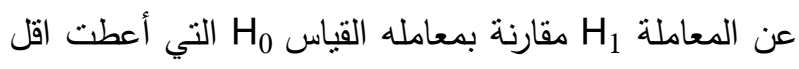

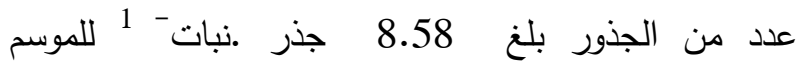

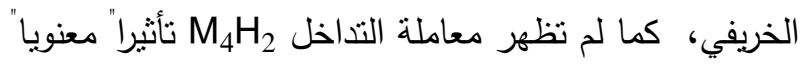


و4.34 غم نبات-1 مقارنة بمعاملة القياس

أعطت اقل وزن جاف للجذور بلغ 3.40 و 2.19 غم نبات -1

للموسمين بالتتابع.
التي أعطت اقل وزن جاف للمجموع الجذري بلغ 3.98

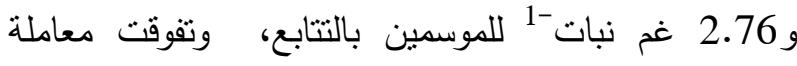

التداخل M بإعطاء أعلى وزن جاف للجذور بلغ 6.49 جدول 4. تأثير الرش بالحديد والزتك وإضافة حامض الهيومك وتداخلهما في عدد الجذور الثانوية لنبات الفاصوليا الخضراء للموسمين الزبيعي والخريفي 2015

\begin{tabular}{|c|c|c|c|c|c|c|c|c|c|c|}
\hline \multicolumn{5}{|c|}{ الموسم الخريفي } & \multicolumn{6}{|c|}{ الموسم الربيعي } \\
\hline المتوسط & M4 & M3 & M2 & M1 & المتوسط & M4 & M3 & M2 & M1 & المعاملات \\
\hline 8.58 & 9.32 & 8.57 & 8.47 & 7.97 & 13.53 & 14.57 & 14.97 & 12.77 & 11.83 & Ho \\
\hline 9.61 & 11.67 & 9.67 & 9.10 & 8.03 & 13.80 & 14.67 & 13.93 & 14.10 & 12.53 & H1 \\
\hline 10.01 & 12.20 & 9.89 & 9.59 & 8.35 & 14.55 & 16.53 & 13.57 & 13.97 & 14.13 & H2 \\
\hline \multirow[t]{3}{*}{0.950} & & \multicolumn{2}{|c|}{1.899} & & N.S & \multicolumn{4}{|c|}{ N.S } & L.S.D5\% \\
\hline & 11.06 & 9.37 & 9.05 & 8.11 & & 15.25 & 14.15 & 13.61 & 12.83 & المتوسط \\
\hline & & 1.096 & & & & & 1.585 & & & $\begin{array}{c}\text { L.S.D } \\
\% 5\end{array}$ \\
\hline
\end{tabular}

جدول5 ـ تأثير الرش بالحديد والزنك وإضافة حامض الهيومك وتداخلهما في الوزن الجاف للجذور(غم نبات -1) لنبات الفاصوليا الخضراء للموسمين الرييعي والخريفي 2015

\begin{tabular}{|c|c|c|c|c|c|c|c|c|c|c|}
\hline \multicolumn{5}{|c|}{ الموسم الخريفي } & \multicolumn{6}{|c|}{ الموسم الربيعي } \\
\hline المتوسط & $\mathbf{M}_{4}$ & $\mathbf{M}_{3}$ & $\mathbf{M}_{2}$ & $\mathbf{M}_{1}$ & المتوسط & $\mathbf{M}_{4}$ & $\mathbf{M}_{3}$ & $\mathbf{M}_{2}$ & $\mathbf{M}_{1}$ & المعاملات \\
\hline 2.76 & 3.42 & 3.18 & 2.24 & 2.19 & 3.98 & 4.49 & 3.94 & 4.11 & 3.40 & $\mathbf{H}_{\mathbf{0}}$ \\
\hline 3.37 & 3.43 & 3.48 & 3.30 & 3.26 & 4.93 & 5.14 & 4.76 & 5.22 & 4.60 & $\mathbf{H}_{1}$ \\
\hline 3.43 & 4.34 & 3.57 & 3.54 & 2.29 & 5.34 & 6.49 & 5.39 & 5.25 & 4.26 & $\mathbf{H}_{2}$ \\
\hline \multirow[t]{3}{*}{0.155} & \multicolumn{4}{|c|}{0.310} & 0.411 & \multicolumn{4}{|c|}{0.822} & L.S.D 5\% \\
\hline & \multirow[t]{2}{*}{3.73} & 3.41 & 3.03 & 2.58 & & 5.37 & 4.69 & 4.86 & 4.08 & المتوسط \\
\hline & & 0.179 & & & & & 0.501 & & & $\begin{array}{c}\text { L.S.D } \\
\mathbf{5 \%}\end{array}$ \\
\hline
\end{tabular}

García, و (12) في تجربة استخدما فيها الكاربون المشع الى ان حامض الهيوميك برتبط مع خلايا انسجة الجذر ويكون

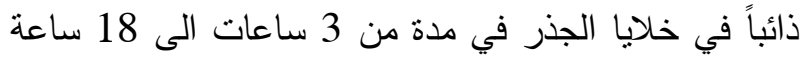

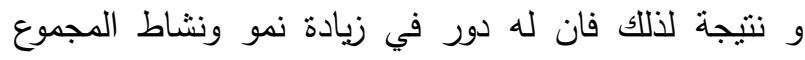

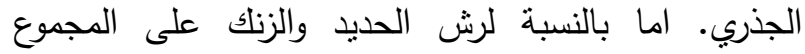
الخضري فقد ادى الى حدوث زيادة في المساحة الورقية والكلوروفيل وقد يكون سبب هذه الزيادة هو ان Fe و من العناصر المهمة في اكمال دورة حياة النبات، حيث ان الحديد يدخل في المكونات الاساسية للخلية النباتية كالسايتوكرومات واسهامه في بناء الكلوروفيل وينشط كثيراً

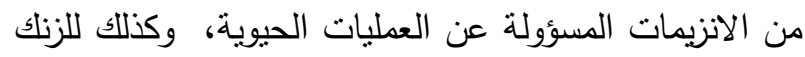
دور مهم في تكوين الحامض الاميني Tryptophan والذي يعد المادة الاساسية لهرمون IAA الضروري لعملية انقسام الخلايا واستطالتها وزيادة عملية التمثيل الكاربوني، وان انهان
ان سبب تفوق معاملات رش الحديد والزنلك واضافة حامض الهيوميك في صفات المجموع الجذري قد يعود الى الدور الكبير للأسمدة العضوية في تزويد النبات بالعناصر الغذائية الكبرى والصغرى فضلا عن تحسين خواص التربة الفيزيائية والكيميائية والحيوية وفي زيادة جاهزية المغذيات الصغرى نتيجة لخلبها ومنع ترسيبها منل الحديد والزنك وخفض ونس

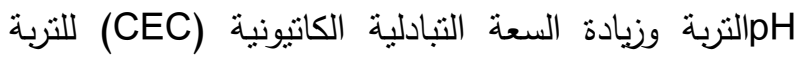
فتزداد النسبة المئوية للعناصر في النبات (3). كما ان لهذه الاسمدة العضوية دورا مهما في توفير بيئة ملائمة لنمو الجذور وتحسين جاهزية العناصر الغذائية (24) ، وانها تعمل على زيادة عدد الجذور الثانوية وقطرها والوزن الطري للمجموع الجذري (27). كما ان حامض الهيوميك سريع الارتباط والدخول الى خلايا انسجة الجذر اذ يرتبط بكميات كبيرة من خلايا الجذر وبساعات قليلة اذ اشار الثار 
255.11 بالتتابع، والتي لم تختلف معنويا مع معاملة M3 للموسم الخريفي ،مقارنة بمعاملة القياس M1 التي أعطت اقل نزكيز للحديد بلغ 220.89 و 203.43 ملغم .كغم للموسمين بالتتابع ، وتفوقت معاملة حامض الهيوميك H2 بإعطاء أعلى تركيز للحديد بالأوراق بلغ 253.41 و 221.72 ملغ كغم -1 للموسمين الربيعي والخريفي بالتتابع، مقارنة بمعاملة القياس التي أعطت اقل تركيز للحديد بلغ 217.25 و واعين 213.10ملغم كغم -للموسمين بالتتابع، وتفوقت معاملة التداخل M4 بإعطاء أعلى تزكيز للحديد في الأوراق بلغ ,

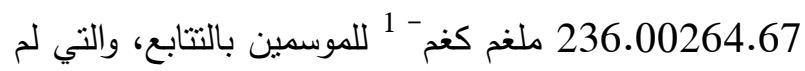
M تختلف معنوبا عن معاملات التداخل M

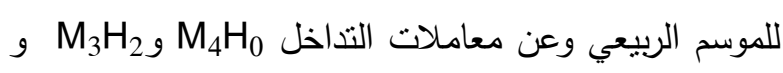
للموسم الخربفي مقارنة بمعاملة القياس M $\mathrm{M}_{3} \mathrm{H}_{1}$ أعطت اقل تزكي للحديد في الأوراق بلغ و 199.7ملغم .كغم -1 للموسمين بالتتابع.

اهمية الاغشية الخلوية ومساهمة الزنك في بنائها ووظائفها يؤثز حتماً في اجزاء عدة من النبات منل الجذور التي يؤثر نقص الزنلك في وظائفها بتأثيره في الاغشية الخلوية للخلايا مما يؤثر في تدفق وانتقال المواد المختلفة داخل الجذور منّ ايونات البوتاســيوم والاحماض الامينية والســــريات

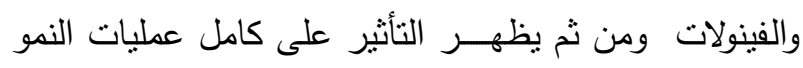
والتكاثز في النبات (14)، كما ان الزنك يؤثر في ايض الكربوهيدرات والبروتينات في الخلية وهذه التأثيرات تتعلق يون مباشرة بعمليات تحول صيخ السكر وكذلك في تأثير العنصر في عملية التمثيل الكاربوني وهذا له صلة مباشرة بتوافر البروتينات والكربوهيدرات اللازمة لعملية النمو وانتاج الاجزاء الخضرية والتكاثربة (25)، وبالتالي فان المحصلة النهائية هي زيادة المجموع الخضري مما ينعكس ايجابيا في زيادة الحاصل.

تركيز الحديد في الاولق (ملفم Fe كغم -1 مادة جافة) تنثير نتائج جدول 6 إلى وجود نأثير معنوي لمعاملات

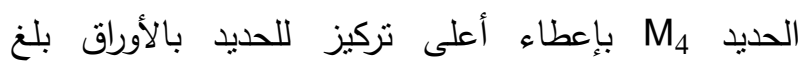
جدول 6. تأثير الرش بالحديد والزتكك وإضافة حامض الهيومك وتداخلهما في تركيز الحديد في الأورلق(ملف Fe .كفر -1 ) لنبات الفاصوليا الخضراء للموسم الربيعي والخريفي 2015

\begin{tabular}{|c|c|c|c|c|c|c|c|c|c|c|}
\hline \multicolumn{5}{|c|}{ الموسم الخريفي } & \multicolumn{6}{|c|}{ الموسم الريبعي } \\
\hline المتوسط & $\mathbf{M}_{4}$ & $\mathbf{M}_{3}$ & $\mathbf{M}_{2}$ & $\mathbf{M}_{1}$ & المتوسط & $\mathbf{M}_{4}$ & $\mathbf{M}_{3}$ & $\mathbf{M}_{2}$ & $\mathbf{M}_{1}$ & المعاملات \\
\hline 213.10 & 232.70 & 213.30 & 206.70 & 199.70 & 217.25 & 242.33 & 235.00 & 200.00 & 191.67 & $\mathbf{H}_{\mathbf{0}}$ \\
\hline 214.60 & 212.00 & 225.00 & 215.70 & 205.70 & 246.50 & 258.33 & 250.33 & 247.37 & 230.00 & $\mathbf{H}_{1}$ \\
\hline 221.72 & 236.00 & 229.70 & 216.30 & 204.90 & 253.41 & 264.67 & 257.00 & 251.00 & 241.00 & $\mathbf{H}_{2}$ \\
\hline \multirow[t]{3}{*}{5.91} & \multicolumn{4}{|c|}{11.82} & 5.69 & \multicolumn{4}{|c|}{11.38} & $\begin{array}{c}\text { L.S.D } \\
\mathbf{5 \%}\end{array}$ \\
\hline & 226.90 & 222.66 & 212.90 & 203.43 & & 255.11 & 247.44 & 232.79 & 220.89 & المتوسط \\
\hline & & 6.12 & & & & & 6.07 & & & $\begin{array}{c}\text { L.S.D } \\
\mathbf{5 \%}\end{array}$ \\
\hline
\end{tabular}

وتفوقت معاملة H2 التي أعطت أعلى تركيز للزنلك بلغ 36.50و 42.90 ملغم كغم-1 مادة جافة للموسمين الربيعي

والخربفي بالتتابع والتي لم تختلف معنوبا عن معاملة

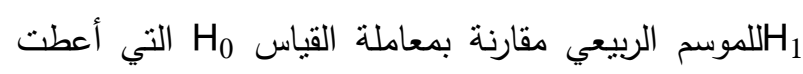
اقل تركيز للزنك بالأوراق بلغ 28.50 و 36.90 ملغم كغم-

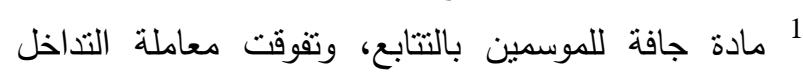
بإعطاء أعلى نزكيز للزنك بلغ 43.00 بلغ 430.30

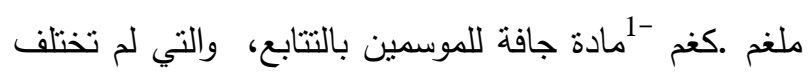

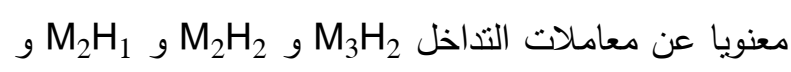
M $\mathrm{M}_{2} \mathrm{H}_{2}$ للموسم الربيعي وعن معاملة $\mathrm{M}_{4} \mathrm{H}_{0}$
تركيز الزنك في الاولق (ملفم Zn كفم ${ }^{-1}$ مادة جافة)

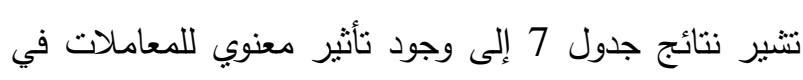

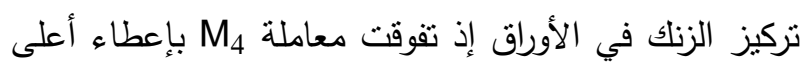

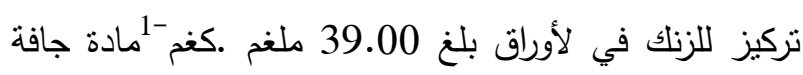

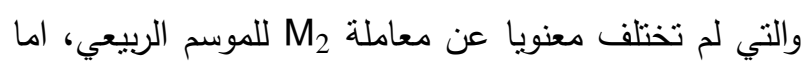

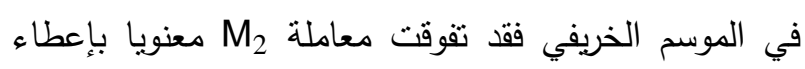

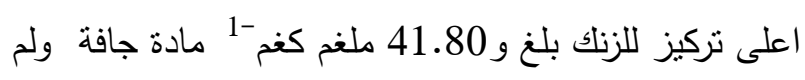

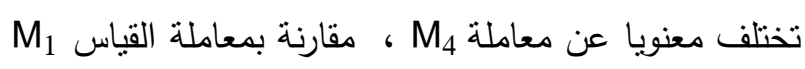

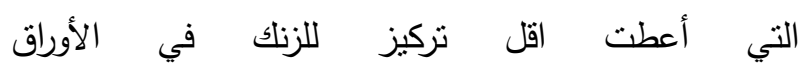

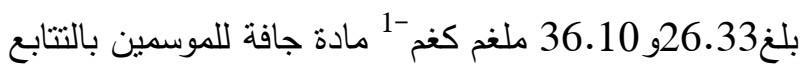


الخريفي مقارنة بمعاملة القياس M

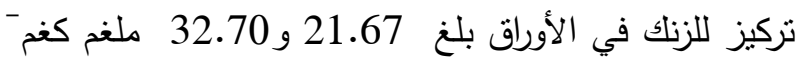
جدول 7. تأثير الرش بالحديد والزنك وإضافة حامض الهيوميك وتداخلهما في تركيز الزنك في الأورلق(ملفم Zn كفم -1 مادة

جافة) لنبات الفاصوليا الخضراء للموسمين الربيعي والخريفي 2015

\begin{tabular}{|c|c|c|c|c|c|c|c|c|c|c|}
\hline \multicolumn{5}{|c|}{ الموسم الخريفي } & \multicolumn{6}{|c|}{ الموسم الربيعي } \\
\hline المتوسط & $\mathbf{M}_{4}$ & $\mathbf{M}_{3}$ & $\mathbf{M}_{2}$ & $\mathbf{M}_{1}$ & المتوسط & $\mathbf{M}_{4}$ & $\mathbf{M}_{3}$ & $\mathbf{M}_{2}$ & $M_{1}$ & المعاملات \\
\hline 36.90 & 34.50 & 37.70 & 43.00 & 32.70 & 28.50 & 34.33 & 26.33 & 31.67 & 21.67 & $\mathbf{H}_{0}$ \\
\hline 38.90 & 40.70 & 42.00 & 37.50 & 35.70 & 33.57 & 39.67 & 30.33 & 37.33 & 27.67 & $\mathbf{H}_{1}$ \\
\hline 42.90 & 46.30 & 40.30 & 45.00 & 40.00 & 36.50 & 43.00 & 33.00 & 40.33 & 29.67 & $\mathbf{H}_{2}$ \\
\hline \multirow[t]{3}{*}{1.532} & \multicolumn{4}{|c|}{3.064} & 5.010 & \multicolumn{4}{|c|}{10.21} & $\begin{array}{c}\text { L.S.D } \\
\mathbf{5 \%}\end{array}$ \\
\hline & \multirow[t]{2}{*}{40.50} & 40.00 & 41.80 & 36.10 & & 39.00 & 29.89 & 36.44 & 26.33 & المتوسط \\
\hline & & 1.614 & & & & & 5.780 & & & $\begin{array}{c}\text { L.S.D } \\
\mathbf{5 \%}\end{array}$ \\
\hline
\end{tabular}

هناك فرق معنوي للنسبة المئوية للنتروجين في الموسم الخريفي مقارنة بمعاملة القياس Ho مئوية للنتروجين بلغت 2.23 و 1.84 \% للموسمين الربيعي والخريفي بالتتابع وتفوقت معاملة التداخل معنويا بإعطاء اعلى نسبة مئوية للنتروجين بلغت 2.40 و 2.19\% للموسمين بالتتابع، والتي لم تختلف معنويا عن معاملة التداخل M ${ }_{1} \mathrm{H}_{2}$ , M $\mathrm{M}_{3} \mathrm{H}_{2} \mathrm{H}_{1} \mathrm{M}_{4} \mathrm{H}_{1}$ مقارنة بمعاملة القياس M للنتروجين بلغت 2.14 و 1.65\% للموسمين بالتتابع.
النسبة|لمئوية للنتروجين في الاوراق (\%) تثير نتائج جدول 8 إلى وجود تأثير معنوي لمعاملات

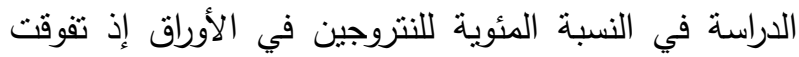
معاملة M معنويا بإعطاء أعلى نسبة مئوية للنتروجين في الني الأوراق بلغت 2.34 و2.04\% للموسمين الربيعي والخريفي بالتتابع والتي لم تختلف عن معاملة M3 للموسم الخريفي

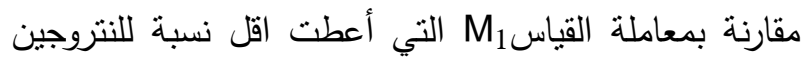

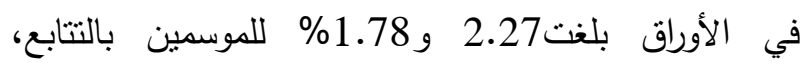
وتقوقت معاملة H2 معنوياً بإعطاء أعلى نسبة مئوية

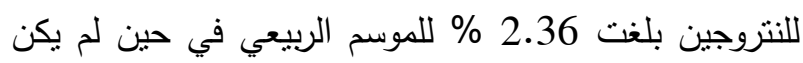
جدول8 ـ تأثير الرش بالحديد والزتك وإضافة حامض الهيوميك وتداخلهما في النسبة المئوية للنتروجين في الأوراق لنبات

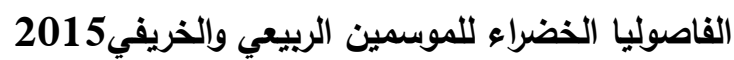

\begin{tabular}{|c|c|c|c|c|c|c|c|c|c|c|}
\hline \multicolumn{5}{|c|}{ الموسم الخريفي } & \multicolumn{6}{|c|}{ الموسم الربيعي } \\
\hline المتوسط & $\mathbf{M}_{4}$ & $\mathbf{M}_{3}$ & $\mathbf{M}_{2}$ & $\mathbf{M}_{1}$ & المتوسط & $\mathbf{M}_{4}$ & $\mathbf{M}_{3}$ & $\mathbf{M}_{2}$ & $\mathbf{M}_{1}$ & المعاملات \\
\hline 1.84 & 1.93 & 2.01 & 1.79 & 1.65 & 2.23 & 2.29 & 2.25 & 2.24 & 2.14 & $\mathbf{H}_{0}$ \\
\hline 1.95 & 2.02 & 2.05 & 1.80 & 1.93 & 2.31 & 2.34 & 2.30 & 2.32 & 2.30 & $\mathbf{H}_{1}$ \\
\hline 1.96 & 2.19 & 2.00 & 1.87 & 1.78 & 2.36 & 2.40 & 2.33 & 2.35 & 2.36 & $\mathbf{H}_{2}$ \\
\hline \multirow[t]{3}{*}{0.127} & \multicolumn{4}{|c|}{0.254} & 0.022 & \multicolumn{4}{|c|}{0.044} & $\begin{array}{c}\text { L.S.D } \\
\mathbf{5 \%}\end{array}$ \\
\hline & \multirow[t]{2}{*}{2.04} & 2.02 & 1.82 & 1.78 & & 2.34 & 2.29 & 2.30 & 2.27 & المتوسط \\
\hline & & 0.147 & & & & & 0.026 & & & $\begin{array}{c}\text { L.S.D } \\
\mathbf{5 \%}\end{array}$ \\
\hline
\end{tabular}

بلغت 0.36 و0.39 \% للموسمين الربيعي والخريفي بالتتابع

النسبة المئوية للفسفور في الاولق (ب) والتي لم تختلف معنويا عن معاملة M3 للموسم الربيعي، تتير نتائج جدول 9 إلى وجود تأثثر معنوي للمعاملات في الاوني

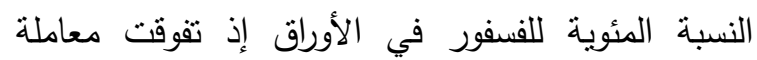
مقارنة بمعاملة القياس M1 التي أعطت اقل نسبة مئوية بلغت 0.33 و0.29 \% للموسمين بالتتابع، وتفوقت معاملة 
معنويا بإعطاء أعلى نسبة مئوية للفسفور بلغت 0.40

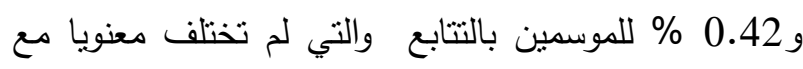
Mع ${ }_{1} \mathrm{H}_{0}$ للموسم الخريفي مقارنة بمعاملة القياس التي أعطت اقل نسبة مئوية للفسفور في الاوراق بلغت 0.30و 0.26 \% للموسمين بالتتابع.
معنويا بإعطاء أعلى نسبة مئوية للفسفور بلغت 0.37

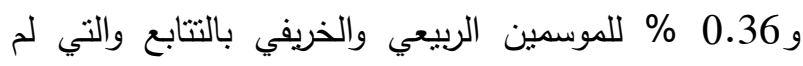
تختلف عن معاملة H $\mathrm{H}_{1}$ القياس H $\mathrm{H}_{0}$ التي أعطت اقل نسبة مئوية بلغت 0.33 و 0

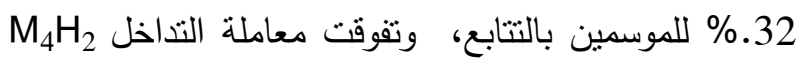
جدول 9. تأثثر الرش بالحديد والزتك واضافة حامض الهيومك وتداخلهما في النسبة المئوية للفسفور في الاورلق لنبات

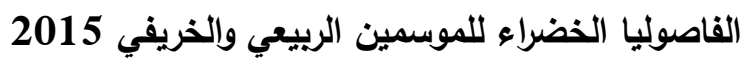

\begin{tabular}{|c|c|c|c|c|c|c|c|c|c|c|}
\hline \multicolumn{5}{|c|}{ الموسم الخريفي } & \multicolumn{6}{|c|}{ الموسم الربيعي } \\
\hline المتوسط & $\mathbf{M}_{4}$ & $M_{3}$ & $\mathbf{M}_{2}$ & $\mathbf{M}_{1}$ & المتوسط & $\mathbf{M}_{4}$ & $\mathbf{M}_{3}$ & $\mathbf{M}_{2}$ & $\mathbf{M}_{1}$ & المعاملات \\
\hline 0.32 & 0.36 & 0.35 & 0.31 & 0.26 & 0.33 & 0.35 & 0.33 & 0.34 & 0.30 & $\mathbf{H}_{0}$ \\
\hline 0.35 & 0.40 & 0.36 & 0.33 & 0.30 & 0.34 & 0.34 & 0.35 & 0.35 & 0.34 & $\mathrm{H}_{1}$ \\
\hline 0.36 & 0.42 & 0.38 & 0.34 & 0.33 & 0.37 & 0.40 & 0.37 & 0.34 & 0.35 & $\mathbf{H}_{2}$ \\
\hline \multirow[t]{3}{*}{0.015} & \multicolumn{4}{|c|}{0.030} & 0.016 & \multicolumn{4}{|c|}{0.032} & L.S.D 5\% \\
\hline & 0.39 & 0.36 & 0.32 & 0.29 & & 0.36 & 0.35 & 0.34 & 0.33 & المتوسط \\
\hline & & 0.017 & & & & & 0.018 & & & $\begin{array}{c}\text { L.S.D } \\
\mathbf{5 \%}\end{array}$ \\
\hline
\end{tabular}

Hللموسم الربيعي بينما تفوقت معاملة H H معنويا بإعطاء

النسبة المئوية للبوتاسيوم في الاورق (خ)

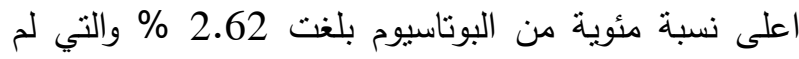

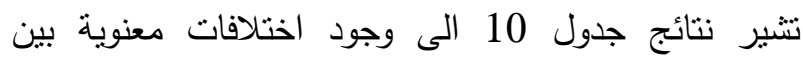
تختلف معنويا عن معاملة H للموسم الخريفي مقارنة بمعاملة اغلب المعاملات في النسبة المئوية للبوتاسيوم في الأوراق اذ القياس H تفوقت معاملة M4 بإعطاء أعلى نسبة مئوية للبوتاسيوم في 2.42و 2.51 \% للموسمين بالتتابع، وتفوقت معاملة الاوراق بلغت 2.69 و 2.68\% للموسمين الربيعي والخريفي

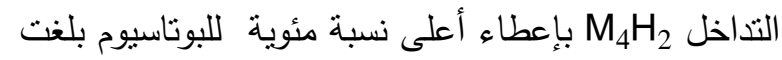
بالتتابع والتي لم تختلف عن معاملة M3 للموسم الخريفي، 2.73 و2.77\% للموسمين بالتتابع والتي لم تختلف معنويا

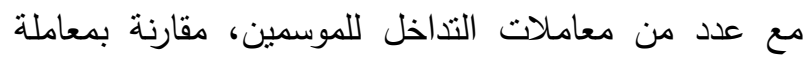
القياس M في الاوراق بلغت 1.79 و 2.40 \% للموسمين بالتتابع.

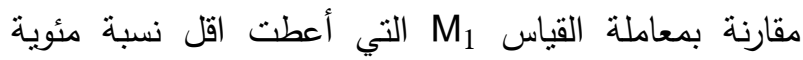
للبوتاسيوم بلغت 2.28 و 2.47\% للموسمين بالتتابع، وتفوقت معاملة H بإعطاء أعلى نسبة مئوية للبوتاسيوم بلغت 2.69 \% والتي لم تختلف معنويا عن معاملة جدول10. تأثير الرش بالحديد والزنك وإضافة حامض الهيومك وتداخلهما في النسبة المئوية للبوتاسيوم في الأورلق (\%) لنبات الفاصوليا الخضراء للموسمين الربيعي والخريفي 2015.

\begin{tabular}{|c|c|c|c|c|c|c|c|c|c|c|}
\hline \multicolumn{5}{|c|}{ الموسم الخريفي } & \multicolumn{6}{|c|}{ الموسم الربيعي } \\
\hline المتوسط & $\mathbf{M}_{4}$ & $\mathbf{M}_{3}$ & $\mathbf{M}_{2}$ & $\mathbf{M}_{1}$ & المتوسط & $\mathbf{M}_{4}$ & $\mathbf{M}_{3}$ & $\mathbf{M}_{2}$ & $\mathbf{M}_{1}$ & المعاملات \\
\hline 2.51 & 2.56 & 2.66 & 2.45 & 2.40 & 2.42 & 2.65 & 2.63 & 2.61 & 1.79 & $\mathbf{H}_{0}$ \\
\hline 2.62 & 2.73 & 2.70 & 2.54 & 2.54 & 2.60 & 2.70 & 2.66 & 2.66 & 2.39 & $\mathbf{H}_{1}$ \\
\hline 2.57 & 2.77 & 2.59 & 2.46 & 2.48 & 2.69 & 2.73 & 2.68 & 2.68 & 2.67 & $\mathbf{H}_{2}$ \\
\hline \multirow[t]{3}{*}{0.116} & \multicolumn{4}{|c|}{0.232} & 0.104 & \multicolumn{4}{|c|}{0.208} & $\begin{array}{c}\text { L.S.D } \\
\mathbf{5 \%}\end{array}$ \\
\hline & \multirow[t]{2}{*}{2.68} & 2.65 & 2.48 & 2.47 & & 2.69 & 2.65 & 2.65 & 2.28 & المتوسط \\
\hline & & 0.133 & & & & & 0.120 & & & $\begin{array}{c}\text { L.S.D } \\
\mathbf{5 \%}\end{array}$ \\
\hline
\end{tabular}


التربة مع مياه الري ادى الى /حدوث زيادة في الأوراق من

العناصر الغذائية N و Pو و و Fe.

\section{REFERENCES}

1. Abdel-Mawgoud, A.M.R.; A. M. ElBassiouny and A., S.D. Abou-Hussein. 2011. Foliar application of amino acids and micronutrients enhance performance of green bean crop under newly reclaimed land conditions. Australian Journal of Basic and Applied Sciences, 5(6): 51-55.

2. Abu Dahi, Y. M. and M. A. Al-younis.1988. Plant Nutrition Guide. Ministry of Higher Education and Scientific Research. Baghdad University-Iraq.pp:411.

3. Agbede, T. M.; S. O. Ojeniyi; and A. J. Adeyemo.2008. Effect of poultry manure on soil physical and chemical properties ، growth and grain yield of sorghum in southern Nijeria. Amr. Eurasian. J. Sustainable Agtic. 2: 72 77.

4. Al-Ajeel, S. A. Al-S.1998 Effect of Salinity and Organic Waste and Nutrition leafy in Tomato in Najaf Desert Area. Ph.D. Dissertation. College of Agriculture, University of Baghdad. Iraq. pp:210.

5. Al-Khafaji, A. H. A. 2015. Effect of Potassium and Spraying Iron and Zinc on the Growth and Yield Mung bean (Vigna radiate L.) Ph.D. Dissertation. Department of Field Crops - College of Agriculture, University of Baghdad. pp:125.

6. Allawi, M. M.2013. Impact of Bio, organic and Chemical Fertilization on the Roots Architectural and Growth and Yield of Pepper Plant (Capsicum annuum L.). Ph.D. Dissertation. Department of Horticulture and Landscape Gardening - College of Agriculture, University of Baghdad.pp: 247.

7. Al-Obeidi, A. A. Z. 2006. Response of Beans (Phaseolus vulgaris L.) to Different Levels of Sulfur Foam and Spray Zinc and Manganese. M.Sc. Thesis. College of Agriculture - University of Baghdad. pp:88.

8. Al-Rikabi, F. H. and, A. J. Al- meshal. 1981. Vegetable Production. Agricultural Technical Institutes Institution. Ministry of Higher Education and Scientific Research. Iraq.

9. Al-Sahaf, F. H. .1989. Applied Plant Nutrition. The Ministry of Higher Education
يلاحظ من نتائج جداول محتوى الاوراق من العناصر الغذائية

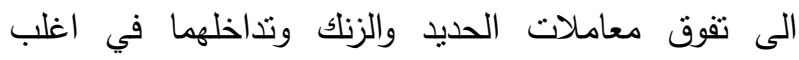
الصفات المقاسة وان سبب زيادة نسبه العناصر الغذائية كالنتروجين والفسفور والبوتاسيوم وتراكمهما في الانسجة

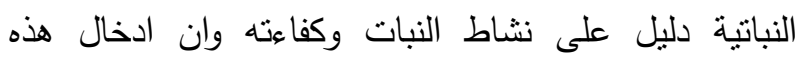

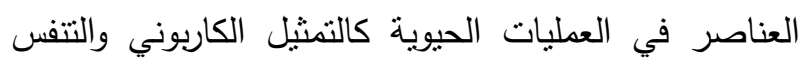
والنتح فضلا عن انقسام الخلايا واستطالتها سيؤثر في زيادة مقدرة النبات في تحسين النمو الخضري والجذري مما يساعد على زيادة كفاءة النبات في امتصاص العناصر الغذائية (9) لعندين وذلك لان بعض العناصر الصغرى ومنها الزنك فان نقصده يودي الى قصور في امكانية الخلية على انتاج البروتين وقد يعود السبب الى انخفاض تواجد مNA وكذللك قلة وجود الرايبوسومات. او ربما يعود ذلك إلى دور العناصر الغذائية الصغرى في زيادة امتصاص النيتروجين والفسفور والبوتاسيوم وتراكمه في الأوراق (4)و (10). ان معاملات التغذية الورقية

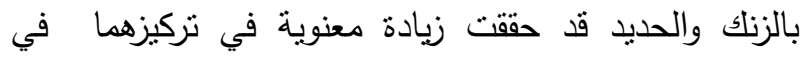
الاوراق وفي كلا الموسمين وقد تعود هذه الزيادة الحاصلة في بلي تركيز الزنكك والحديد في الاوراق الى زيادة كميتها المضافة في محلول الرش ومن ثم زيادة كمية الممتص منها من قبل الاوريل اوراق النبات. اتققت هذه النتيجة مع ما توصن لتهل اليه Poshtmasari

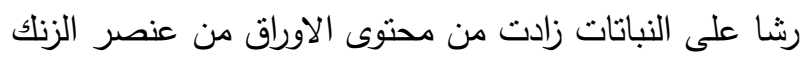
وكذلك وجد (5)ان رش الحديد والزنك على المجموع الخضري من التي

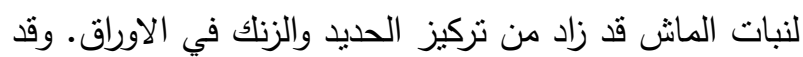
يعود سبب زيادة العناصر والكبرى والصغرى في النبات الى لى رلى دور أحماض الهيوميك في زيادة نراكيز النتروجين والفسفور

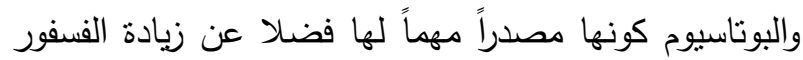
والبوتاسيوم الجاهز في التربة ومن ثم امتصاصها من قبل النبات، والذي ربما زاد من المساحة السطحية للامتصاص في جذوره (6) ،أو ربما لدورها المباثر في زيادة المساحة السطحية للجذور نتيجة لزيادة استطالة خلايا الجذور والانقسام الخيطي في الخلايا المولدة للتفرعات الجذرية بسبب لئب

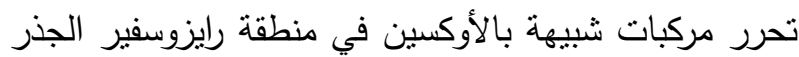

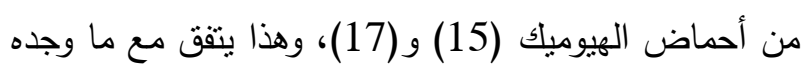
Yousif

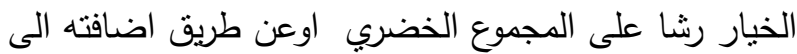


and Scientific Research -Higher Education printing house-Iraq. pp: 260.

10. Amer, A. S. S.; 1981. Effect of some Growth Regulators and some Minor Elements on Growth and Yield of tomato. M.Sc. Thesis. Faculty of Agric. Sci. Moshtohor. Zagazig University. Egypt.pp:136.

11. Awad, K. M.1987. Fertilization and Soil Fertility. Ministry of Higher Education and Scientific Research - University of Basra.pp:285.

12. Berbara, R.L.L.; and A.C. García .2014. Humic Substances and Plant Defense Metabolism. Springer Science and Business Media, New York, pp 297-319.

13. Borowski, E and S, Michaáek. 2011. The effect of foliar fertilization of french bean with iron salts and ureaon some physiological processes in plants relative to iron uptake and translocationin leaves. Acta Sci. Pol., HortorumCultus.10(2): 183-193.

14. Cakmak, I.; and H. Marschner. 1988. Increase in membrane permeability and exudation in roots of Zinc deficient plants. J. Plant Physiol. 132: 356-361.

15. Canellas, L.P.; D. J. Dantas and N. O. Aguiar. 2011. Probing the hormonal activity of fractionated molecular humic omponents in tomato auxin mutants. Ann. Appl. Biol., 159:202-211

16. Chapman, H. D.; and P. F. Pratt. 1961. Method of Analysis for Soil ,Plant and Water. University of California, Division of Agricultural Sciences.93(1):68.

17. Dobbss, L. B.;L. B. Canellas; F. L. Olivares, N. O. Aguiar, L. E. Pereira Peres, M. Azevedo, R. Spaccini, A. Piccolo and A. R. Fac-Anha. 2010. Bioactivity of chemically transformed humic matter from vermicompost on plant root growth. J. Agric. Food Chem., 58: 3681-3688

18. Elkhatib, H.A.; S.M. Gabr and S.H. Brengi. 2008. Impact of humic acid amendments on alleviating the harmful effects of cadmium in radish and bean plants. Alexandria Science Exchange Journal. 29(2): 263-282.

19. El-Sahoeky, M. and K. M. Wahib . 1990. Applications in The Design and Analysis of Experiments. Ministry of Higher Education and Scientific Research. Baghdad University.
Dar al-Hikma for printing and publishing. pp:488.

20. Hassan, A. A.1989. Fruiting Vegetables. Dar Al Arabia for Publishing and Distribution, Cairo.pp:301

21. Ibrahim, Ehab A and W.A. Ramadan. 2015.Effect of Zinc Foliar Spray Alone and Combined with Humic acid Or/and Chitosan on Growth, Nutrient Elements Content and Yield of Dry Bean (Phaseolus vulgaris L.) Plants Sown at Different Dates. Scientia Horticulturae. 184: 101-105.

22. Laura, A.,D.L. Rosa,A.P. Emilio and G. A. Gonzalez-Aguilar. 2010 .Fruit and Vegetable Phytochemicals :Chemistry, Nutrition Value, and Stability.Wile.Blackwell Publication USA. 1: 53-88.

23. Lge, O.2012. Comparison of the Quality Aspects of Organic and Conventional Green Beans (Phaseolus vulgaris L.).M.Sc. Thesis of master. Guelph, Ontario, Canada. pp:58.

24. Magdoff, F. and R. R. Weil. 2005. Soil Organic Matter In Sustainable Agriculture. CRC press. Boca Raton London.pp.524.

25. Marschner , H. ,1995.Mineral Nutrition of Higher Plants $.2^{\text {nd }}$ ed. Sandiego: Academic press .pp:710.

26. Meganid, A. S.; H.S. Al-Zahrani. and M.S. EL-Metwally. 2015. Effect of humic acid application on growth and chlorophyll contents of common bean plants (Phaseolus vulgaris L.) under salinity stress conditions. International Journal of Innovative Research in Science, Engineering and Technology.4 (5):2651-2660

27. Mora, V.;R. Baigorri;V. Bacaicoa, A. Zamarreno and J. M. Garcia-Mina. 2012. The humic acid-induced changes in the root concentration of nitric oxide, IAA and ethylene do not explain the changes in root architecture caused by humic acid in cucumber. Environ. Exp. Bot., 76:24-32.

28. Nejad, R.H.; F. Najafi; P. Arvin and R. Firuzeh. 2014.Study different levels of zinc sulphate $\left(\mathrm{ZnSO}_{4}\right)$ on fresh and dry weight, leaf area, relative water content and total protein in bean (Phaseolus vulgaris L.) plant. Bull. Env. Pharmacol. Life Sci. 3(6): 144-151.

29. Olaniyi, J. O.; and A.T. Ajibola. 2008. Effects of inorganic and organic fertilizers application on the growth, fruit yield and quality of tomato (Lycopersicon esculentum 
Mill ). J. Appl. Biosciences. 8 (1): 236 -242. 30. Poshtmasari, H. K.; M. A. Bahmanyar; H. Pirdashti and M.A.A. Shad. 2008. Effect of Zn rates and application forms on protein and some micronutrients accumulation in common bean (Phaseolus vulgaris L.). Pak. J. of Biol. Sci. 11(7):1042 - 1046.

31. Tisdale , S.L.; W.L. Nelson ; J.D. Beaton and J.L. Havlin .1997. Soil Fertility and
Fertilization Prentices . Hall of India New Delhi .pp:449.

32. Yousif, K.H. 2011. Effet of Humic Acid, Biofertilizer (EM-1) and Application Methods on Growth, flowering and yield of Cucumber (cucumis sativus L .).M.Sc. in AgriculturalDept. of Horticulture and Landscape Gardening-University of Duhok, Kurdistan Region Iraq.pp:167. 